\title{
A SYSTEMATIC APPROACH FOR VE PARTNERS SELECTION USING THE SCOR MODEL AND THE AHP METHOD
}

\author{
Felipe Bittencourt, Ricardo J. Rabelo \\ Federal University of Santa Catarina, BRAZIL \\ felbit@das.ufsc.br, rabelo@das.ufsc.br
}

\begin{abstract}
This paper presents an approach to help VE managers in the selection of the most suitable enterprises to compose a VE (Virtual Enterprise). Applying the Analytic Hierarchy Process (AHP) method having as basis metrics presented in the SCOR model, the VE manager can have a more robust view upon the partners' importance and bill of material's items criticality in a given business opportunity.
\end{abstract}

\section{INTRODUCTION}

The enterprises have faced markets in constant changing, global competition, and shorter and shorter technologic cycles. With the popularization of the Internet and the proliferation of the electronic markets, the ability to have competitive advantage and to survive in so dynamic markets, depends on its organization flexibility, information availability, effective coordination of decisions and actions, and permanent or sporadic relations with other enterprises willing to face new business opportunities (Pereira, 2000). Besides that, looking at reducing costs and other correlated objectives, like changing fixed cost to variable and reducing its assets, many enterprises are allocating some of its less critic activities to third part firms (ATKearney, 2003). The concept of Virtual Enterprises (VE) emerges from this scenario. Actually it is relatively new in the literature and very new yet in terms of industry acceptance.

A VE is a dynamic, temporary and logical aggregation of autonomous enterprises that cooperate with each other as a strategic answer to attend a given opportunity or to cope with a specific need, and whose operation is achieved by a coordinated sharing of skills, resources and information, totally enabled by computer networks (Rabelo et al., 2004a).

Many efforts have been spent by the scientific community in order to address each new dilemma that the Virtual Enterprise paradigm brings up. Since VEs are composed of autonomous entities and frequently created with short and medium term objectives, the process of creating VEs must be carried out with more and more agility while the global cost for that must be minimized (Davulcu et all., 1999). However, the VE creation is a complex problem. The traditional ways enterprises 
select their suppliers are no longer adequate at all in a VE scenario regarding the weaker trust among newer partners, the metrics used to evaluate them, and the need for a much quicker selection of them out of potential dozens of candidates.

In this sense, this paper proposes a systematic approach to assist the so called VE Manager in the selection of the most suitable partners for a given VE. For that, the SCOR model and the AHP (Analytical Hierarchical Process) method are applied in a combined way once the enterprises have bid for a given proposal.

This paper is organized as follows. Chapter 1 has highlighted the new trend for collaborative work and the need for more agile selection of partners. Chapter 2 stresses a bit the problem of VE partner's search and selection. Chapter 3 introduces the proposed systematic approach for partner's selection. Chapter 4 comments some results already achieved in terms of prototype implementation. Finally, Chapter 5 presents some conclusions.

\section{PARTNERS' SEARCH AND SELECTION PROBLEM}

Nowadays there is a clear trend towards business collaboration. Enterprises are building long term relationships in order to benefit from preferences or exclusivity when bidding to an item. It is assumed that enterprises should help to each other improving their own processes in order to beneficiate both sides, even if it demands a short term effort (Neverwire, 2002). Here trust arises in importance. In very concrete terms, collaboration in a trustful environment involves the sharing of principles. One perspective of these principles involves the sharing of metrics to measure the partners' performance and the way they are measured and understood. On the other hand, in a more volatile relationship, usually done among partners who are collaborating for the first time and perhaps will no longer work together again, it is quite difficult to guarantee a minimum basis of trust.

Under this perspective of trust, some works divide enterprises into two main groups (Neverwire, 2002): large enterprises, and SMEs. The first group uses to work in a Collaborative Commerce environment. They build long term relationships with their suppliers and eventually with their suppliers' suppliers, providing low tax financing for raw-material purchase, production line improvement, employees training, etc. In this group there is time for establishing common principles and rules, including continuous improvement and learning processes. The second group, generally represented by SMEs, use to focus more on a Market Oriented approach, where transactions are only an exchange of goods for payment. Usually this is about the singular delegation of a task from a buyer to a seller. Enterprises stay autonomous and do business per individual transactions. There are no formal agreements binding the seller to the buyer. It might have some kind of cooperation between them, but this lasts only until that business opportunity is finished. This kind of relationship requires from enterprises to be more agile and flexible as a way to guarantee their survival in the increasingly competitive environment. In this group there is not much room for establishing wider principles of trust, which makes them to be connected via a fragile line of common conduct and sometimes working with a not recommendable level of risk.

More recently, and perhaps as a third / hybrid group, there is the Virtual Breeding Environments (VBE) (Camarinha et al., 2004). In general, VBEs can be 
seen as an evolution of the classic concept of cluster of enterprises. A VBE is a group of enterprises from any sectors that decides to make part of a long-term collaborative community where they can benefit from each other in common business opportunities, in the sharing of technologic knowledge, in training activities, and many other advantages. Nevertheless, for partners' selection purposes, the key aspect here is that they share the same code of conduct on how to make businesses together as well as on how they can be evaluated. Despite these common rules, enterprises keep autonomous for leveraging businesses with outsiders, both working with long term relations with a given large enterprise and to make businesses with other SMEs opportunistically.

When partners should be selected to create a Virtual Enterprise, this is made using the same decisions that purchase departments take daily when selecting bid suppliers for the involved products. The purchasing literature states that selection and management of the right supplier is crucial to obtain the desired level of quality, comprising delivery time, right price, the necessary level of technical support, and the desired level of service. According to (Dobler and Burt, 1996), buyers must take six important supplier-oriented actions in order to satisfy these requirements:

1. Develop and maintain a consistent supplier base;

2. Address the appropriate strategic and tactical issues;

3. Ensure that potential suppliers are carefully evaluated and that they have the potential to be effective suppliers;

4. Decide whether to use competitive bidding or negotiation as the basis for source selection;

5. Either select the appropriate help or be the team leader responsible for this task;

6. Manage the selected supplier to ensure it fulfills the order's requirements.

A considerably number of firms does this by the means of suppliers' performance measurement programs that are based on metrics. Metrics are used to evaluate past performance of processes in order to take control actions or only to do benchmarking (Goranson, 1999). There are hundreds of metrics that can be applied to select partners. One of the most comprehensive set of metrics is provided by SCOR (Supply-Chain Operations Reference model). What are the most suitable metrics to be applied to and upon a given set of suppliers for a given business? Do suppliers implement metrics in the same way? Are there semantics conflicts on how to interpret them? Are there some metrics more important than others for that given business? If so, how much important are they? Can I also make some qualitative analysis instead of a purely quantitative computation? These are examples of answers that a manager should have for a proper selection of VE partners when using metrics.

Actually, the suppliers' evaluation varies in nature, criticality, complexity, and monetary value of the purchase to be made. Seeing the literature, it seems there is a clear lack of supporting methodologies to help managers in those decisions. Besides that, it has been observed that several works make that analysis focusing on adequate metrics for each process/partner of the chain or VE instead of considering the VE as a whole.

Aiming at contributing to this problem, next chapter presents the proposed approach to assist VE managers in the partners' selection. It considers the VE as a 
whole as well as that in a VE scenario every business opportunity is per se different from one to another hence requiring a careful analysis about the metrics to be used.

\section{THE PROPOSED SYSTEMATIC APPROACH}

When a partner is clearly better then its competitors the selection becomes a very simple task. However, practice shows it is quite rare. The choosing of the best partner is becoming complex and complex as modern business requires the application of a number of metrics against partners simultaneously with metrics having different degrees of importance (weights) in each business.

The identification of the key metrics and their respective weights is typically accomplished by a committee of individuals involved in the purchasing. Regarding the difficulty to assign weights to metrics, this work applies the Analytic Hierarchy Process - AHP - method (Zahedi, 1986).

Three important assumptions are considered in this work. The first one is that all enterprises would belong to a given VBE, so VEs are to be created based on a VBE's rules. The second one is that, as a VBE, the SCOR model was chosen as the source of metrics that cold be applied in the partners' selection and evaluation. The third one is the existence of a global historical database (HDB) in the VBE, which would contain an historic of all the transactions among the VBE members, keeping the metrics' set updated and contributing to measure the performance of each of the enterprises.

In general, the proposed systematic approach is carried out in ten almost totally sequential steps, within which the AHP method is used. Actually, these steps fit the main phases of the VE creation life cycle: collaboration opportunity characterization, rough VE plan, partners' identification, negotiation, detailed VE planning and VE launching (Camarinha et al., 2005).

\section{i) Business Opportunity Specification (BO):}

This phase is characterized by the identification of an opportunity to do business with the enterprises inside the VBE related to a given product. The enterprise which has identified this $\mathrm{BO}$, by default, will act as the VE manager and so will be responsible for searching and selecting the partners that match the product's global specifications.

ii) Bill of Materials (BOM): Having on hands he BO's specifications, the VO manager is provided with its $\mathrm{BOM}$ in order to compose a preliminary VE plan. It is through this BOM that the potential partners will be found, ranked and later selected. This VE plan must embody all the aspects to attend the BO, from the delivery and transport service (when necessary) to the last level of product decomposition.

iii) First Call for Tenders: By means of using BOM it is necessary to find suppliers interested and capable of supply each of its items. Calls for tender containing basic (but essential) information about the product's parts, dates, price limits and other preferences are spread out over the VBE (partners search phase) and potential / interested partners can make a bid for them. The sending of only basic information is interesting as it avoids enterprises to receive a bunch of unnecessary information 
(and sometimes huge ones in the case of CAD models) for their preliminary analysis. Besides that, some pre-processing in the VBE's members list can be made considering the members' profiles so that even this basic announcement can be sent to potential members only.

iv) Analytic Hierarchy Process (AHP): In parallel to step iii, the VE manager should evaluate the criticality of the BOM's items in the context of every / specific BO. For that, the Analytic Hierarchy Process (Zahedi, 1986) is applied. The VE manager is then assisted with the AHP method in order to 1) assign a weight for the product's parts and then for the partners, 2) to choose the most suitable metrics and weight them 3 ) to assign a weight for the metrics' scales.

Figure 1 illustrates part of the idea / process. The FBTextile is a product composed basically of four parts: buttons, embroidery, fabric and labels. The VO manager assigns (in a subjective way) the levels of importance (in the form of weights) to each product's part. Besides that, (s)he selects the most suitable metrics for each part. In the case of buttons, the metrics would be price, quality and delivery date. These metrics in turn should also have different levels of importance considering that specific BO. For instance, the VO manager assigns 55\%, 20\% and $25 \%$ for those metrics, respectively. Finally, each metrics has some specific ranges that will be used to classify the bidders. Having all these weights settled, the VE manager can realize, for instance, that, considering the weights of the buttons and of the delivery time, if $s($ he) could find some partner who can deliver buttons at the contracted date with at least $95 \%$ of certainty, then $1.2 \%$ of the whole "success" of the VE is "guaranteed".

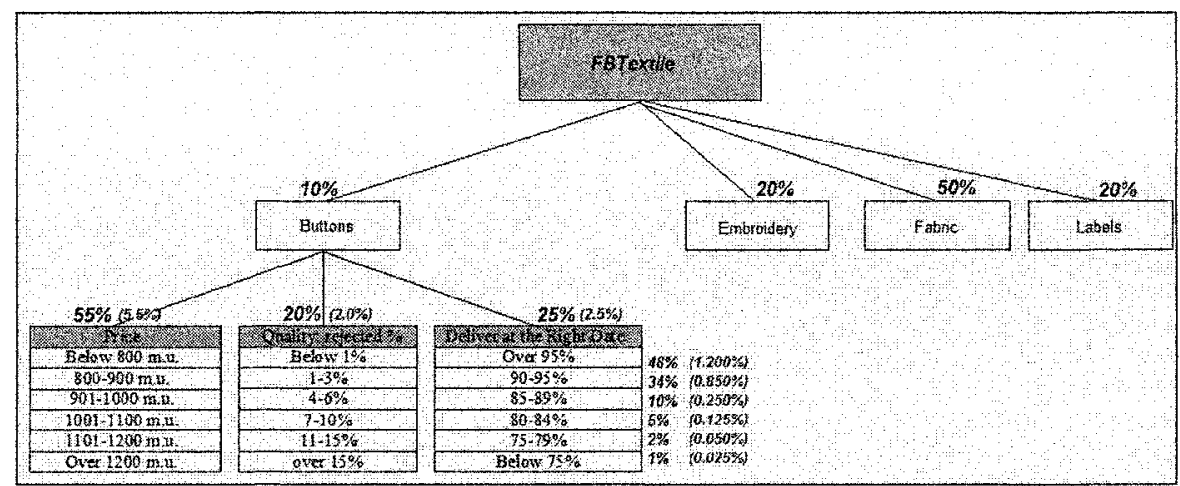

Figure 1 - The Analytic Hierarchy Process to weight a Virtual Enterprise

iv.1) Weighting the importance of each Supplier: Comparing the different possible VEs that can be formed with the bidders is not an easy task. Suppose we have a configuration where the supplier of Buttons, in Figure 1, is an outstanding enterprise, but the Fabric quality of another supplier is very poor. In another configuration, the Button and Fabric suppliers are both good, but not the best. Which the configuration is the most suitable to address the BO? The AHP method is used here to weight the importance of each kind of supplier, and the result is that the Buttons supplier is responsible for $10 \%$ of the $\mathrm{BO}$ success. 
iv.2) Choosing the Best Metrics to evaluate each Supplier: A common problem faced by the enterprises when doing business is the lack of standardization among the metrics used to evaluate the processes. It is recommended that the decision makers from all the enterprises get together to create, discuss and analyze these metrics, trying to foreseen the future businesses that will be carried out among the VBE participants. The SCOR model presents a comprehensive and huge set of metrics (called "criteria" in Figure 2) and respective ratings that can be used in the partners' selection. Anyway, the VBE Board can decide to use some additional particular metrics regarding its specificities. Metrics should be selected and agreed by the VBE members, prior to any business, no to only as a mean to provide further evaluations, but also, and extremely important, as a mean to have decision criteria transparent and homogeneous so reinforcing trust building. Metrics must reflect the success factor, the competition basis, of the given sector, which is more and more customer-driven (Raynor, 2003).

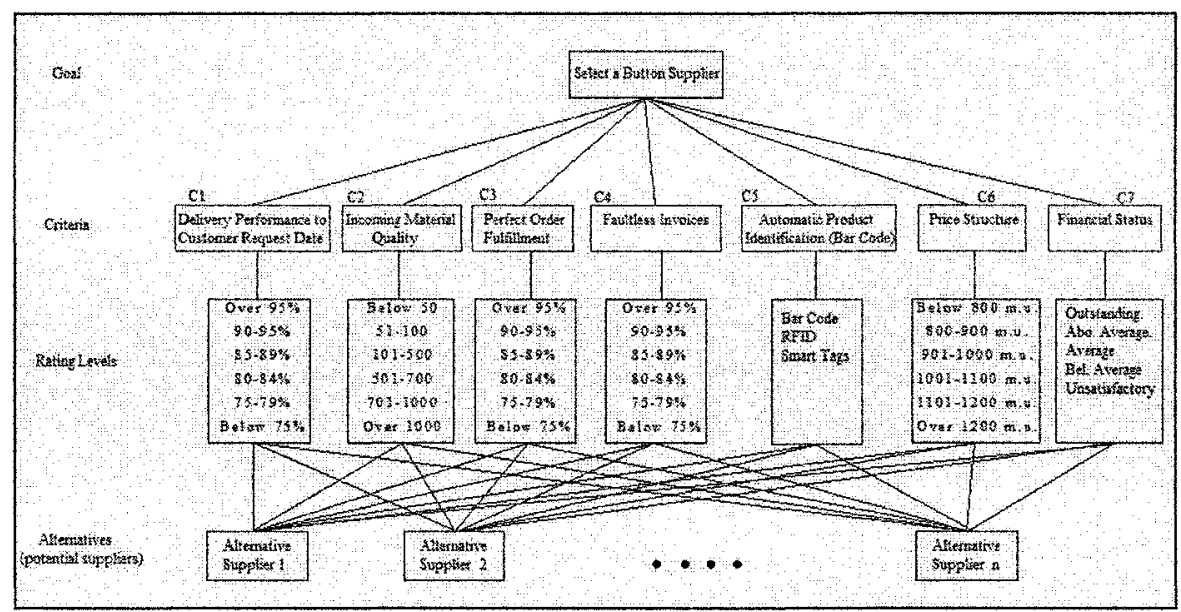

Figure 2 - SCOR metrics to measure suppliers for a BOM item

Once the metrics are selected, it is necessary to assign weights of importance to each of them. The graph in Figure 3 shows the resulted weights for the metrics presented in Figure 2. As stated by (Lee, $\mathrm{Ha}$ and $\mathrm{Kim}, 2001$ ), where a set of hierarchical metrics are used with the AHP Method, it is not necessary to consider all the metrics presented in the Figure 3 to continue a deeper analysis. Applying the Pareto's principle, it is easy to verify that C6 (47\%), C1 (21\%) and C2 (15\%) represent together $83 \%$ percent of the weights. Thus, they represent the "key metrics" when selecting the Button suppliers for this specific BO.

iv.3) Weighting the Metrics' Scale: The metrics' scales are used to place the supplier value for the metric in a pre-specified range. The scale, in the same way as its metric, must also be chosen previous to the VBE conception. One could suppose that the scales presented in Figure 1, are all part of a linear function, but it is usually not true. For instance, a Delivery with $95 \%$ of certainty must be strongly preferred 
than a $90 \%$ delivery. However, anything below $85 \%$ could have the same preference since it would not feet to the BO in consideration. Then, the AHP is once again employed to give weights for each of the scales' steps. In Figure 1, the Delivery at the Right Date criterion with more than $95 \%$ of certainty was weighted with $48 \%$ of importance.

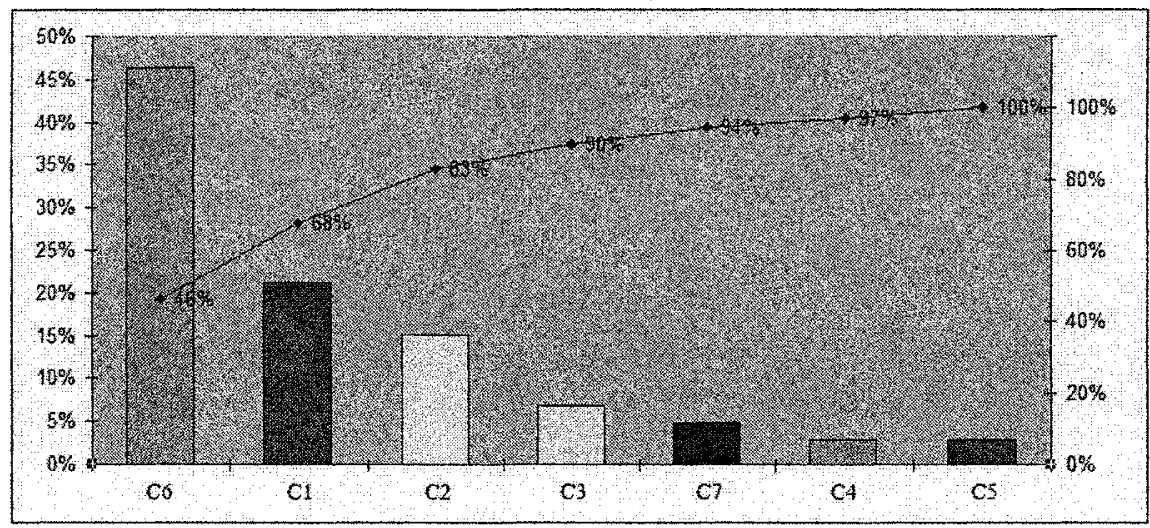

Figure 3 - Weight for the metrics selected to measure suppliers for a BOM item

It is important to highlight that these considerations represent the main basis for selecting partners as a non-isolated, single process, but rather, as a part in the whole. Yet, because product's parts are inter-related and are dependent to each other. It is also important to consider here the matter related to metrics that are "feasible" to be applied in long-term relationships and in short-term relationships. As mentioned in Chapter 2, a SCOR-based model is more robust and can be applied in BOs whose accomplishment will be done by the VBE's members. This means that the metrics used by its members should be implemented in their enterprises with a common criteria and interpretation and that this will be constantly audited by the VBE Board in order to guarantee that members are applying them properly in-house. This is fundamental for the trust building process inside the VBE as partners will only participate in businesses which they are sure that competitors will be evaluated/selected having the same interpretation about the metrics. Therefore, it is feasible to require for a given $\mathrm{BO}$ metrics like stocks turn-over, scrap average, leadtime, financial health and others. Besides this, benchmarking can be (as has been more and more) used to compare partners as well as a mean to make partners to compare with each other. On the other side, when enterprises need to work with non-VBE members, especially in very short-term relationships (only for that $\mathrm{BO}$ ), metrics like those ones are not feasible, not useful at all and not trustful as enterprises don't have them implemented and, if they have it, they may have it using different interpretations and ways of measurement. Therefore, in these cases, the only choice is the application of "common sense" metrics, like general quality, final price and delivery date.

v) Send Complete Announce: After having the metrics chosen and weighted, the complete announce is sent to the enterprises which have bidden positively so that they can refine their bid now being aware about the global criteria that will be 
indeed used in the selection of partners. This awareness is very much important for trust building. After receiving the tenders, those enterprises make their final offer.

vi) Generate possible scheduling alternatives: As many enterprises can bid for the same product item, it is natural to have a number of possible VEs and hence different valid schedule alternatives.

vii) Instantiate the Metrics values: Applying a function on each possible VE for a given $\mathrm{BO}$, the VE manager can instantiate the metrics matrix according to the partners current bit and their past performances. This is executed consulting the VBE's historical database. This function can be a simple average mean, or a weighted average mean, giving higher values to more recent performances.

viii) VE Schedules Ranking: With the instantiation of those metric values and their respective weights in every possible $\mathrm{VE}$, it is possible to go through the BOM list giving values for each node, from the BOM bottom to the top. The value achieved at the top represents the overall score for that given VE configuration. Therefore, the highest score would express the most suitable set of enterprises and VE plan. Some authors, like (Goranson, 1999), defend that is not very secure to estimate the future performance of an enterprise by its past accomplishments, but rather for the capacity it has to perform well in the future. Figure 4 illustrates this idea. In this figure, is quite obvious that Enterprise A has much more probability to perform better than Enterprise B in the future. Applying this principle at the VE level, it means that a set of "snapshots" taken along the time with the ranking generated could be shown to the VE Manager so that he could have complementary information for his decision. In order to better present this multi-level perspective, the Figure 4 below, besides showing snapshots of individual enterprises along the time, could be used to show instantiations of $\mathrm{VE}$ alternatives/composition along the time as well. For example, enterprise A would represent VE alternative A and enterprise B the VE alternative B.

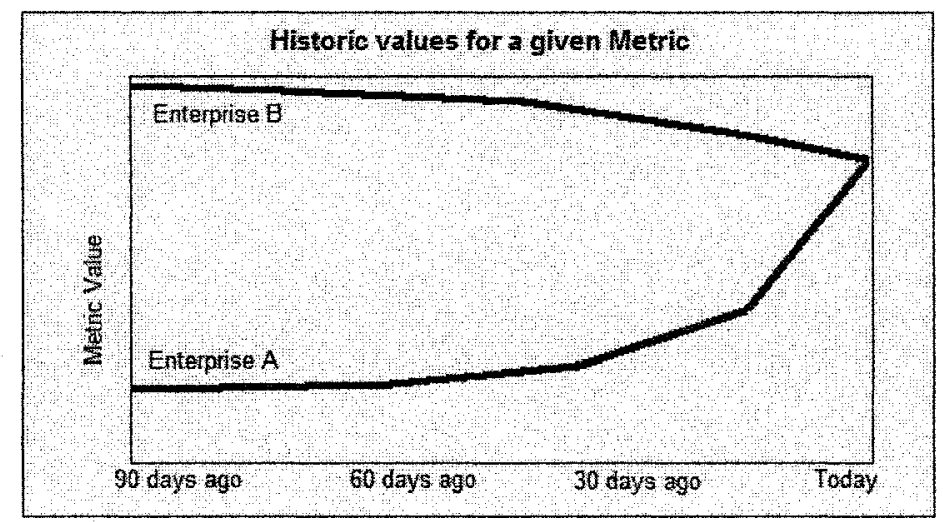

Figure 4-Comparison between two enterprises past performances

ix) Negotiations: Sometimes, even after have ranked the possible VEs and the results announcement, there is some room for negotiation and eventual refinements in the VE plan. 
x) Operation phase: Once the VE is settled and partners contracted, the operation phase can start. Ending this proposed systematic approach, the VE manager should monitor the partners' performance and update the VBE historical database for further use in next BOs.

\section{PRELIMINARY PROTOTYPE}

In order to exercise the framework, a multi-agent system prototype has been developed. This system was developed having the Schmidt's system as the basis (Rabelo et al., 2004b). Each enterprise of the VBE is modeled as an agent and the information gathering from the enterprises to compose a VE is provided by means of sending mobile agents to them. The system uses the AGLETS platform and uses KQML and XML to exchange information between the VBE members. The system has two main classes of agents: VBE Manager, and the Enterprise Agents.

The VBE Manager agent is responsible for keeping the historical database containing the information about all the businesses carried out in the VBE, and also for handling the request for information from the Enterprise Agents.

The Enterprise Agent is composed by the BOM Module, AHP module, Scheduling module and Rank module. Once a given enterprise acts as the VE Manager of a given BO, this agent is allowed to send mobile agents to the other enterprises to collect their biddings. The BOM module is used to create the list of materials which will be the input for the AHP and Scheduling modules. The mobile agent is responsible for delivering and requesting announces for bidding, and metric values from the VBE Manager. The AHP module assists decision makers to weight the most important criteria to select suppliers for that specific BOM. The Scheduling module generates all the possible VE based on the delivery constraints of the BOM items announced and on the answers from the interested enterprises. Finally the Rank module works together with the mobile agent to gather the metric values, computing the weighted criteria and generating a rank based on the results of each VE scheduled by the Scheduling model.

\section{CONCLUSIONS AND OUTLOOKS}

The right partner's selection is extremely important, and it should not be based only in cost and delivery, but also in other metrics which must be aligned with the enterprise strategic planning. This work has proposed a systematic approach for the partners' search and selection, based on the history of past trading metrics. Those metrics were selected from the widely accepted model, SCOR - Supply Chain Operational Reference, by the use of a multi criteria decision making called AHP Analytic Hierarchy Process.

As it has been explained, the application of the AHP method in the VE context seemed quite appropriate for partners' selection. However, it requires a good experience from the VE manager when assigning weights to products' items and partners. Some other methodology could then be applied to assist him in this process. 
The use of the bill of materials as the main supporting bases for the proposed systematic approach seems to fit very well "stable" / already existing products. Other types of "products", like services and one-of-a-kind, can make use of this approach but perhaps with several additional considerations and different time constraints to form a VE.

The effective coordination and integration between the VE functions are also far beyond the desired level. There are many gaps regarding the mastering of logistics' costs, and the monitoring and improvement of enterprises' internal processes. It is not possible, in that case, to skip essential evolution steps. This means that enterprises should envisage specific initiatives focused on the VE paradigm requirements.

\section{Acknowledgments}

This work has been developed in the scope of the Brazilian IFM project, funded by $\mathrm{MCT} / \mathrm{CNPq}$, and IST IP FP6 ECOLEAD project, funded by EC.

\section{REFERENCES}

A.T.Kearney, GEO Awards Special Survey - As Novas Fronteiras da Gestão da Cadeia de Suprimentos na América Latina, 2003.

Camarinha-Matos, L.M.; Afsarmanesh, H.; Ollus, M. (Eds) - Virtual Organizations, Springer, 2005.

Davulcu, H., Kifer, M., Pokorny, L. R., Dawson, S. - Modeling and Analysis of Interactions in Virtual Enterprises, Ninth International Workshop on Research Issues on Data Engineering: Information Technology for Virtual Enterprises, March 1999.

Dobler, D.W., Burt, D. N., "Purchasing and Supply Chain Management: Text and Cases", McGraw-Hill, Sixth Edition, 1996.

Goranson, H.T., The Agile Virtual Enterprise - Cases, Metric, Tools, 1999, Quorum Books.

Lee, E. K, S., Ha, S., Kim, K., "Supplier Selection and Management System Considering Relationships in Supply Chain Management", IEEE Transactions on Engineering Management, vol. 48, no 3, August 2001.LEE and KIN, 2001,

Neverwire, Inc., Collaborative Commerce: Compelling Benefits, Significant Obstacles, 2002.

Pereira, A. M. C., Formaçåo de Empresas Virtuais com Agentes Inteligentes, tese Doutorado, Faculdade de Engenharia da Universidade do Porto, novembro 2000.

Rabelo, R. J.; Pereira-Klen, A.; Klen, E. R., Effective Management of Dynamic Supply Chains, in International Journal of Networking and Virtual Organizations, 2004a.

Rabelo, R. J.; Wangham, M. S.; Schmidt, R.; Fraga, J. S., Trust building in the creation of virtual enterprises in mobile agent based architectures, Proceedings PRO-VE'2003, Kluwer Academics Publishers, pp. 65-72, 2004b.

Raynor, M. E., Deloitte Research - Inside Outsourcing, Deloitte Consulting, 2003.

Supply-Chain Council: http://www.supply-chain.org

Zahedi F., "The analytic hierarchy process: a survey of the method and its applications", Interface 16, 96108, 1986. http://www.interfaces.smeal.psu.edu/ 